\title{
Simbología Gráfica Anatómica en el Proceso de Comunicación
}

\author{
Anatomical Graphic Symbolism in the Communication Process
}

Ricardo Jorge Losardo ${ }^{1,3}$ \& Octavio Binvignat ${ }^{2,3}$

LOSARDO, R. J. \& BINVIGNAT, O. Simbología gráfica anatómica en el proceso de comunicación. Int. J. Morphol., 39(3):739-741, 2021.

RESUMEN: Las ciencias de la comunicación mejoran la organización de la vida en sociedad. En la interdisciplinaridad que la caracteriza se nutre también de la anatomía. La simbología gráfica anatómica, por ejemplo, la calavera o cabeza ósea, por su carácter universal, facilita el proceso de comunicación y advierte sobre potenciales daños de la salud, a veces de consideraciones mortales. Este artículo destaca la participación de la anatomía en los procesos de comunicación.

PALABRAS CLAVE: Anatomía; Comunicación; Simbología; Advertencia sanitaria; Seguridad y salud.

\section{INTRODUCCIÓN}

El proceso de comunicación es tan antiguo como la misma humanidad. Si bien la palabra (o lenguaje hablado) es uno de las formas de comunicación más utilizadas; las señas o gestos, los dibujos y las escrituras, la acompañaron en la historia y la evolución del hombre y su lenguaje (de la Cruz-Lablanca, 2001; Vera, 2014; Rodas-Villagrán, 2017).

Por otra parte, los huesos del cuerpo fueron los que llamaron la primera atención de la anatomía de los seres vivos. En nuestro continente, en Mesoamérica, desde hace más de 3.000 años la gran mayoría de sus pueblos veneraban los huesos de sus antepasados como si fueran representaciones de sus dioses, en especial sus calaveras, que consideraban un modo de comunicación con el otro mundo (Reyes-García, 2014).

Pero serían los mexicas o aztecas quienes demostraron una mayor devoción por el símbolo de la calavera, traspasando los umbrales del culto familiar, trasladándolo a templos y objetos de poder.

De esta manera, con la simbología gráfica anatómica confluyen estas dos disciplinas, la comunicación y la anatomía, alrededor de la "calavera" o cabeza ósea como figura o dibujo.

\section{SIMBOLOGÍA GRÁFICA ANATÓMICA Y ADVER- TENCIAS SANITARIAS}

Los huesos del cuerpo, como la calavera o cabeza ósea, tienen un significado a la hora de la comunicación: precaución, cuidado, advertencia, peligro, tóxico, veneno, muerte, etc. (Fig. 1).

Estos pictogramas ("picto" del latín y "grama" del griego: pintado y escrito) son signos que se refieren a posibles daños para la salud, de magnitud considerable, y que pueden tener consecuencias mortales (Fig. 2). Entonces, la consulta al médico es obligada si no se respeta la recomendación. Los utilizan los organismos, públicos y privados, nacionales e internacionales, con el fin de proteger a la población, a veces en su rol de consumidores. Guían al público con el fin de tomar decisiones correctas. Se da en todos los ámbitos sociales: en el trabajo, lugares educacionales y recreativos, en el hogar, etc. Esta señalización está ligada a la seguridad en el ser humano y en especial de los pacientes (Rodríguez-Herrera et al., 2019). También indica que el personal que deba manipular aquellos productos especiales etiquetados con esta simbología deba utilizar elementos de protección personal específico (Prada-Pérez de Azpeitía, 2012).

Los "símbolos gráficos" son fundamentales para dar información cuando las palabras escritas no son suficientes o completas. Estos símbolos por su gran impacto visual, ya

\footnotetext{
${ }^{1}$ Escuela de Posgrado, Facultad de Medicina, Universidad del Salvador (USAL), Buenos Aires, Argentina.

${ }^{2}$ Escuela de Medicina, Universidad de Talca (UTAL), Talca, Chile.

${ }^{3}$ Academia Panamericana de Historia de la Medicina y Academia Panamericana de Anatomía.
} 

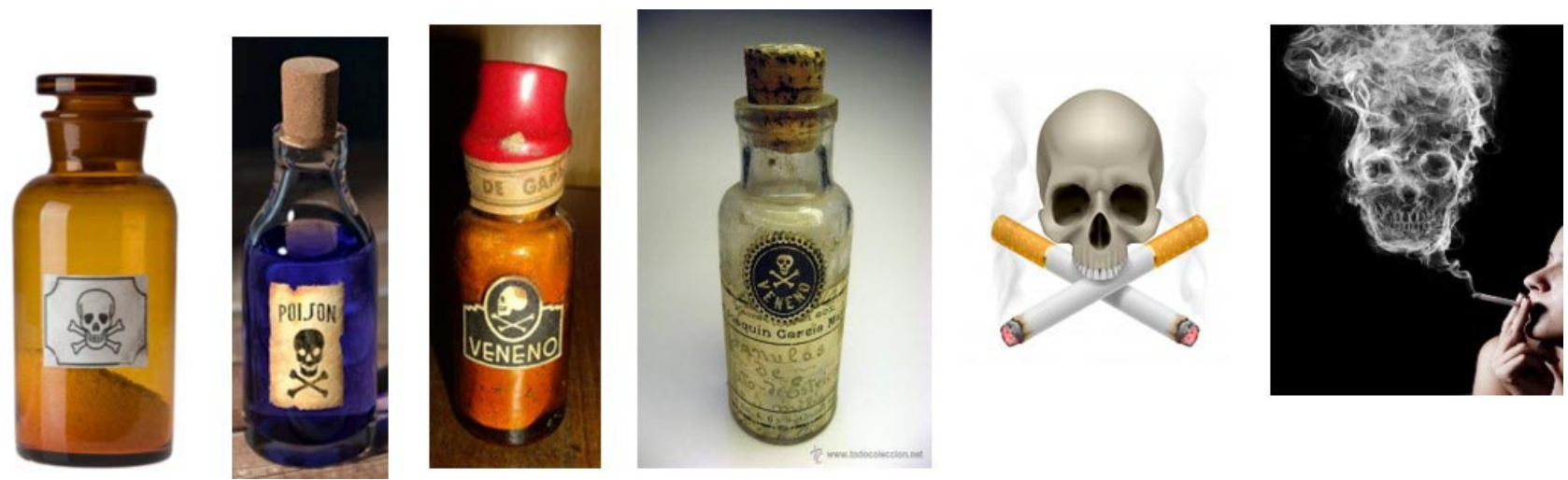

Fig. 1. Etiqueta de precaución, veneno, peligro, atención, cuide su salud, utilizando estructuras óseas anatómicas.

que su contenido es compacto, benefician la comunicación. Recordemos, por otro lado, que el "lenguaje escrito" consta de palabras y números y se expresa en distintos idiomas.

Estos símbolos tienen dos características: a) unifican el mensaje, evitando la proliferación de símbolos gráficos; y b) universalizan el mensaje, ayudando a superar las barreras idiomáticas de los países.

También hay sociedades o sectas, iniciadas en el siglo XIX, en universidades europeas, conformadas por miembros de familias distinguidas, que ejercían como jueces, banqueros, gobernantes, etc., que utilizaban simbología gráfica anatómica (calaveras y otros huesos). En los rituales de iniciación se usaban estos materiales anatómicos.

La historia demuestra que ya en la Edad Media había agrupaciones que empleaban esta simbología, con un propósito de mensaje oculto o secreto. El recorrido en la historia de esta simbología, basada en el esqueleto humano, demuestra que su significado y utilización fue variando y acomodándose a los tiempos; y tiene sus raíces en la Antigüedad (Mesopotamia, Antiguo Egipto, China, etc.).

\section{DISCUSIÓN}

La palabra comunicación deriva del latín "communicatio" que significa compartir, participar en algo o poner en común.

El proceso comunicativo está constituido por una serie de factores que ocurren entre un "emisor" y un "receptor", es bidireccional, con el fin de que un "mensaje" sea transmitido. Aparte de estos tres elementos es necesario además un "código" (o lenguaje) y un "canal de comunicación" (o medio usado) que sean reconocidos por el emisor y el receptor. Debemos agregar otro factor: el "contexto" (o circunstancias donde se desarrolla la comunicación). De esta manera, se logra un proceso de envío y una recepción del mensaje.

La comunicación puede realizarse básicamente de tres maneras: verbales u orales (a través de las palabras), no verbal (gestual) y gráfica (lecto-escritura). En este último se encuentra nuestra simbología gráfica anatómica: la calavera o cabeza ósea.
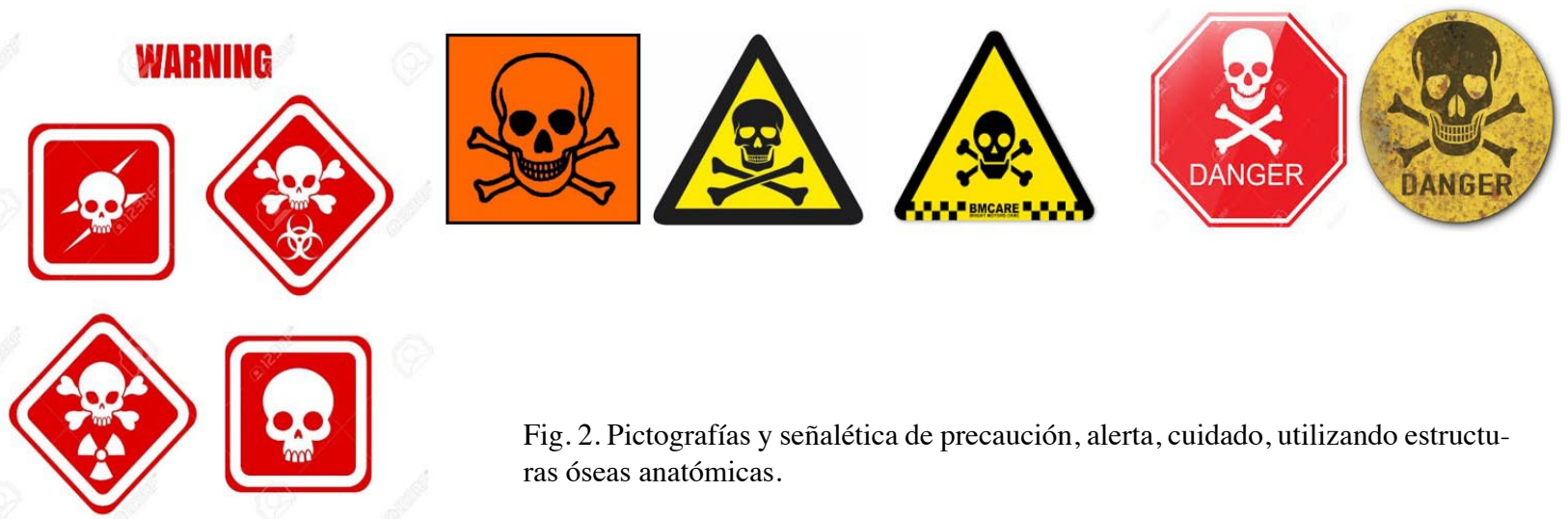

Fig. 2. Pictografías y señalética de precaución, alerta, cuidado, utilizando estructuras óseas anatómicas. 
La palabra calavera proviene del latín "calvaria", que significa cráneo o conjunto de huesos de la cabeza que se mantienen unidos y que han sido eliminados sus tejidos blandos (piel, músculos, etc.). Es símbolo de muerte, señal de peligro y sustancia tóxica, entre las más frecuentes. Luego de la desintegración o descomposición del cuerpo en el proceso de la muerte, el esqueleto es sólo lo que queda, es lo inmortal. Es lo que perdura después de la muerte. La calavera que alojaba el cerebro con sus conocimientos e ideas, implica así la supervivencia del primero sobre el segundo. Como representación es muy simbólico: el individuo que existió, el que fue... es la prueba que hubo vida. Además, desde un punto de vista socio-cultural iguala a las razas y a ambos sexos, al perder su cubierta: los tejidos blandos y la piel. Es decir, comprende a todos y no excluye a nadie (Fig. 2).

La idea de la calavera está asociada a diversos ámbitos culturales en poblaciones pasadas y actuales, y que llevan milenios. Su espectro de interpretación es amplio, desde su visión como un trofeo, una máscara, relacionadas al culto o ritos religiosos, etc. (Jung, 2002; Rubio de Miguel, 2004; Carod-Artal, 2012; Ramos-Martín, 2015). En todos ellos, se destaca el valor simbólico de esta parte del cuerpo y su relevancia en los procesos socio-culturales destinados a reforzar la memoria colectiva de esas comunidades. La calavera como reliquia puede representar la totalidad del ser y la esencia vital del individuo.

El mensaje para que sea efectivo debe ser de fácil comprensión, expresar objetivamente lo que se pretende decir y únicamente lo intencionado. El pictograma de la calavera o cabeza ósea logra este propósito y permite que el proceso comunicativo cumpla con su función de organización de la vida en sociedad.

\section{CONCLUSIÓN}

La "calavera" aporta su valor y ayuda a mejorar la comunicación. Es un signo de carácter universal. Su significado e interpretación son unívocos: es claro y efectivo. Transmite un concepto, idea o información que son familiares para todo el mundo, superando las barreras idiomáticas y culturales. La anatomía, a través de la "cabeza ósea", colabora y permite el efecto deseado en las ciencias de la comunicación. Este artículo destaca la utilidad de la anatomía en los procesos de comunicación.

LOSARDO, R. J. \& BINVIGNAT, O. Simbología gráfica anatómica en el proceso de comunicación. Int.J.Morphol., 39(3):739$741,2021$.
SUMMARY: Communication sciences improve the organization of life in society. In the interdisciplinarity that characterizes it, it also draws on anatomy. The anatomical graphic symbology, for example, the skull or bony head, due to its universal nature, facilitates the communication process and warns of potential health damages, sometimes of mortal considerations. This article highlights the participation of anatomy in communication processes.

KEYWORDS: Anatomy; Communication; Symbols; Health warning; Safety and health.

\section{REFERENCIAS BIBLIOGRÁFICAS}

Carod-Artal, F. J. El culto a los cráneos. Cabezas trofeo y tzantzas en la América precolombina. Rev. Neurol., 55 (2):111-20, 2012.

de la Cruz-Lablanca, I. Comunicación efectiva y trabajo en equipo, Aula Mentor. Gobierno de España, 2001.

Jung, C. G. El hombre y sus símbolos. Paidós Ibérica, Barcelona, 2002.

Prada-Pérez de Azpeitia, F. I. Nuevos pictogramas de productos químicos peligrosos. Anales Real Soc. Española Quím., 108(3):247-57, 2012.

Ramos-Martín, J. El tratamiento ritual del cráneo entre los Númidas. Tabona, Rev. Prehistoria y Arqueología, 21:47-74, 2015.

Reyes-García, M. G. The skull symbol: the pendular crisis between the idol function in the santa muerte and the catrina's icon. Discurso Visual. Rev. Artes Visuales, $3^{a}$ época, 33, 2014.

Rodas-Villagrán, E. Y. Comunicación efectiva y trabajo en equipo.Tesis de Grado. Universidad Rafael Landívar. Quetzaltenango, Guatemala, 2017.

Rodríguez-Herrera, R.; Losardo, R. J. \& Binvignat, O. La Anatomía humana como disciplina indispensable en la seguridad de los pacientes. Int. J. Morphol., 37(1):241-50, 2019.

Rubio de Miguel, I. Rituales de cráneos y enterramiento en el Neolítico pre cerámico del Próximo Oriente. Departamento de Prehistoria y Arqueología, Universidad Autónoma de Madrid (UAM). Cuadernos de Prehistoria y Arqueología (CUPAUAM) 30:27-45, 2004.

Vera, F. Comunicación Efectiva. Universidad de Aconcagua, Chile, 2014.

Dirección para correspondencia:

Prof. Dr. Ricardo J. Losardo

Escuela de Posgrado

Facultad de Medicina

Universidad del Salvador

Av. Córdoba 1601 (C.P. 1055)

Buenos Aires

ARGENTINA

E-mail: ricardo.losardo@usal.edu.ar

Recibido : 16-12-2020

Aceptado: 11-03-2021 